\title{
Reduction of Electrical Losses' Analysis on Distribution Systems with Distributed Generation and Energy Storage Systems
}

\author{
N.M. Neto' ${ }^{1}$, M. R. C. Albertini ${ }^{1}$, W. B. De Melo ${ }^{1}$, M. V. B. Mendonça ${ }^{1}$, A. J. P. R. Júnior ${ }^{1}$, F. A. M. \\ Moura $^{1}$ \\ and J. R. Camacho ${ }^{2}$ \\ Electrical Engineering Department, ${ }^{1}$ Universidade Federal do Triângulo Mineiro, Uberaba - Minas Gerais, Brazil \\ Electrical Engineering Faculty, ${ }^{2}$ Universidade Federal de Uberlândia, Uberlândia - Minas Gerais, Brazil \\ madeleine.albertini@uftm.edu.br, fabricio.moura@uftm.edu.br, IEEE Member.
}

\begin{abstract}
The increasing use of distributed generation in the Electric Power Systems has brought these several problems, since the controllers of these systems must take into account one more variable for any decisions. Within this context, there was a special emphasis on the use of electric energy storage systems to reduce losses, with the allocation of them as a load at the overgeneration points and to reduce system losses at peak demand points. This article presents an analysis of the distributed generation to compare the electrical losses using electrical energy storage. The technique used to estimate the electric energy generation of a photovoltaic system in one day, according to temperature and irradiation data, was the application of artificial neural networks. Thus, the storage element appropriate to the demand and generation levels was first defined and the OpenDSS tool was used to perform the study of the load flow and to measure the effect of the use of these storage systems in the IEEE 37 bus network. Using energy storage in this application has proved to be advantageous, reducing the losses of active power at the peaks and reducing over-generation during the day, measured as crucial for the future of the distribution.
\end{abstract}

\section{Key words}

Technical losses, energy storage system, distributed generation, artificial neural network, openDSS.

\section{Introduction}

In the last two years, the demand for electricity has been growing at around $3.3 \%$ per year throughout Brazil [1], and this projection is expected to rise to $3.6 \%$ per year. This growth is due to the industrial expansion and addition of new residential charges throughout the country.

Distributed generation is in high expansion, thanks to the development of electric energy production through wind energy and the insertion of solar energy in the matrix [2]. In Brazil there is considerable average solar irradiance, a contributing factor for the growth of the solar matrix, together with the population's access to the possibility of selling all the difference between its active power generated and demand.
It can be seen that in the residential case, the generation and demand curves are not match, since during the day only stand-by or continuous operation devices, such as refrigerators, are connected during the day and, at night, large loads such as showers, and multiple electronic devices and lighting are triggered. On the other hand, photovoltaic generation provides energy proportional to instantaneous irradiation.

However, ONS, National Operator of the Electric System, is already worried and respects the changes that the installation of photovoltaic panels in roofs and solar plants will bring to the system. The variability of these types of generation makes it difficult to control the generation of the already installed generating units, since the actions taken by the ONS are taken according to the system load flow, being able to reach surplus generation points. In fact, ONS has concerns about the impossibility of fully controlling generation, which will also come from households [3].

This problem is aggravated by the non-alignment of the solar and wind generation curves with the consumption curves of the whole system. In a distribution network with predominantly residential load curves, consumption peaks occur around $7 \mathrm{pm}$, while photovoltaic power peaks cools around 12 o'clock and wind power peaks are intermittent.

All this raises a new problem for the electric system: possibility of surplus generation [4]. The surplus generation can cause, among others, the following situations to the network:

1) Overvoltage;

2) Frequency variation;

3) Increased losses;

4) Load flow reversal;

5) Instability.

Voltage and frequency are important for power quality settings and may damage loads if they are not within their 
permissible limits. The increase in losses is due to the high conduction of current in the line. There is also possibility of inverting the power flow in the transformers and the system can reach instability due to the unwanted opening of the power angle [5].

Electrical Energy Storage Systems (ESAs) are important elements in energy distribution systems [6] and can be used in:

1) Demand and energy match: electricity can be stored at surplus generation points, eliminating the need to reduce the generation of other sources, keeping production constant, since constant production generates savings.

2) Energy quality: when properly sized and implemented, it can provide electricity to consumers without fluctuations or interruptions and overcome problems such as voltage variations, peaks or harmonics.

3) Accommodation of renewable technologies: ESAs can soften or even eliminate the variability of the generation curves of these sources for constant use at another time.

AEE systems can still reduce the technical losses of the system by analyzing the curves referred to above and reallocating the distributed generation at times when the system will benefit. This storage allocation, in an electrical way linked to geographic, will alleviate the system, being able to reduce the total technical losses, by the alteration of the power flow.

\section{Metodology}

In order to verify the effect of the insertion of electrical energy storage systems, storage and distributed generation will be inserted in strategic locations, according to study [5] of the IEEE 37-bus power system [20]. Figure 1 shows the regions of concentration of the charges.

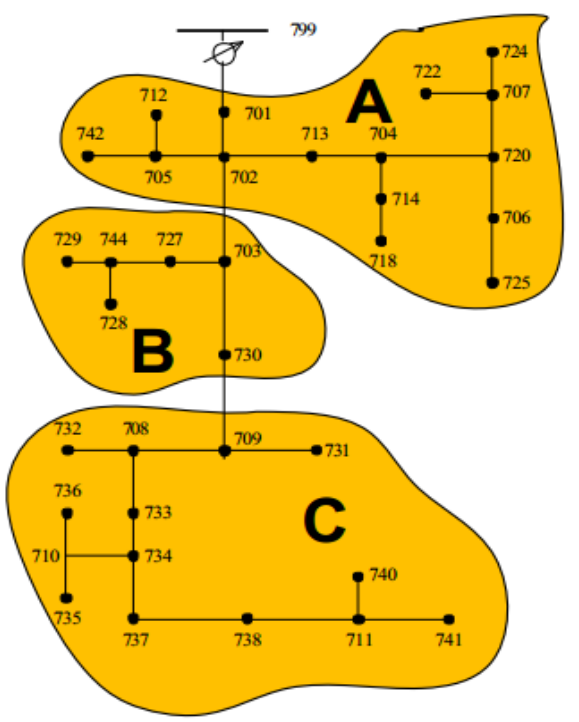

Fig. 1. Load concentration regions of the IEEE 37 system [5].
The distributed generation will be estimated through the use of a neural network, which will be trained with the set of inputs: irradiation, temperature, plate temperature, which target is also provided: the power generated from a given period of time. With the weights of each input set by the already trained network, the system inputs become the irradiance, temperature and plate temperature, for another period of time, where the output will be the estimated PV generation curve.

In the OpenDSS software, the 37-bus IEEE system is simulated in order to define the total installed load in the system, which is multiplied by a typical normalized residential demand curve [8], returning the demand curve.

With the curve of generation and demand hands, the difference between them defines the surplus generation and the hours in which the warehouses will be loaded. The storage rate and the total energy stored in the EEA system, as well as the discharge rate in the system, are then calculated at the established night time.

Finally, case studies will be carried out with the distributed generation and the allocation of the storers in the buses, raising the active and reactive losses and maximum and minimum voltages found in the system, in each case. The entire process was performed according to the flow chart of figure 2 :

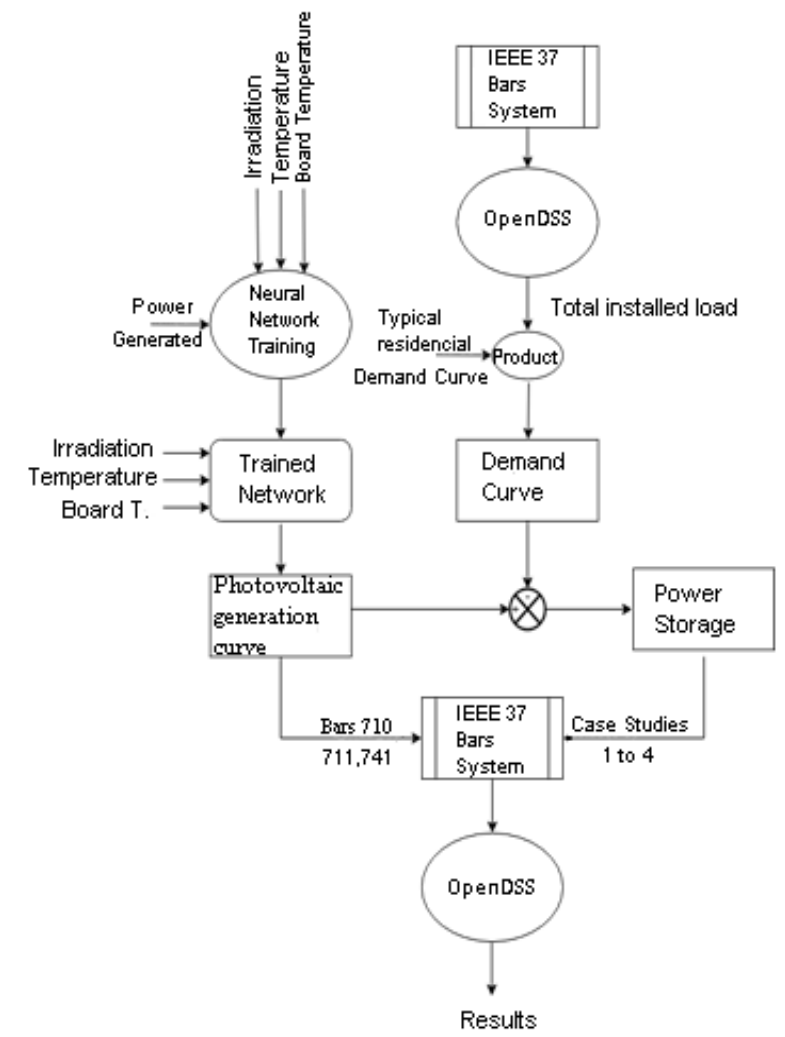

Fig. 2. Flowchart of the methodology.

\section{A. Daily Photovoltaic Generation}




\begin{tabular}{|c|c|}
\hline \multicolumn{2}{|c|}{$\begin{array}{l}\text { Electric performance under the conditions of } \\
\text { irradiance of } 1000 \mathrm{~W} / \mathrm{m}^{2}, \mathrm{AM}=1,5 \text {, and cell } \\
\text { temperature of } 25^{\circ} \mathrm{C} \text { (STC) }\end{array}$} \\
\hline Maximum Power: Pmax $(\mathrm{W})$ & $235 W(0 \%+5 \%)$ \\
\hline Maximum Power Voltage : $V_{\text {mpp }}(V)$ & $30,5 \mathrm{~V}$ \\
\hline Max Power Current: Impp $(A)$ & $7,71 A$ \\
\hline Open Circuit Voltage: Voc $(\mathrm{V})$ & $37 \mathrm{~V}$ \\
\hline Short Circuit Current: Isc $(A)$ & $8,4 A_{1}$ \\
\hline Maximum Voltage $(V)$ & $1000 \mathrm{~V}$ \\
\hline Temperature coefficient of $V_{o c}$ & $-0,4049 \% / \circ \mathrm{C}$ \\
\hline Temperature coefficient of Isc: & $0,0825 \% / \circ \mathrm{C}$ \\
\hline \multicolumn{2}{|c|}{$\begin{array}{l}\text { Electrical performance in } 800 \mathrm{~W} / \mathrm{m}^{2}, \mathrm{NOCT} 20^{\circ} \mathrm{C} \\
\mathrm{AM}=1,5 \text {. Wind speed of } 1 \mathrm{~m} / \mathrm{s} \text {. }\end{array}$} \\
\hline Maximum Power: Pmax (W) & $172 \mathrm{~W}$ \\
\hline Maximum Power Voltage : $V_{\text {mpp }}(V)$ & $27,7 \mathrm{~V}$ \\
\hline Max Power Current: Impp $(A)$ & $6,2 \mathrm{~A}$ \\
\hline Open Circuit Voltage: Voc $(\mathrm{V})$ & $33,9 \mathrm{~V}$ \\
\hline Short Circuit Current: Isc (A) & $6,8 \mathrm{~A}$ \\
\hline
\end{tabular}

Figure 3 - Electrical characteristics of the solar plate [5].

As the solar base plate of the matrix, the solar plate type JT235PC of polycrystalline silicon, of Jetin Solar company was used a solar plate with the characteristics showed above in Figure 3.

For this study, the total of 7000 solar plates were used to obtain surplus generation. By means of the irradiation and temperature data of the city of Uberlândia, of October of 2015 [5] and application of these in a neural network, the values of the total power will be predicted.

\section{B. Multi-layered Neural Networks}

Neural networks are interesting contours for problems with long or non-convergent solutions. Multilayer architecture has universal approximation capability and flexibility to form quality solutions to a broad class of problems, from the same learning algorithm. [9].

The multilayer neural networks provide the neurons in two or more processing layers. There will always be at least one input layer and one output layer. The output layer consists of only one neuron (the perceptron) and the inputlayer neurons have the role of distributing each network input to all neurons in the subsequent layer.

Figure 6 [11] shows the model of a neuron, a fundamental unit of information processing of a neural network. It has three basic elements: a set of input synapses, weighted by a synaptic weight. A sum join, which will sum the weightweighted input signals and an activation function, for neuron output saturation

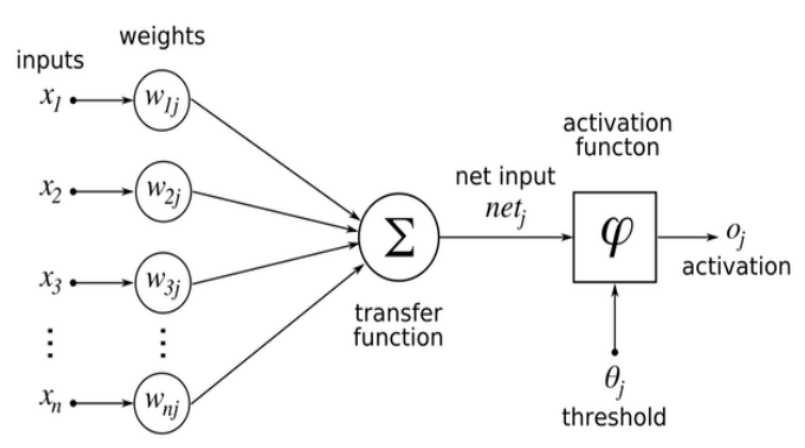

Fig. 4. Neuron model
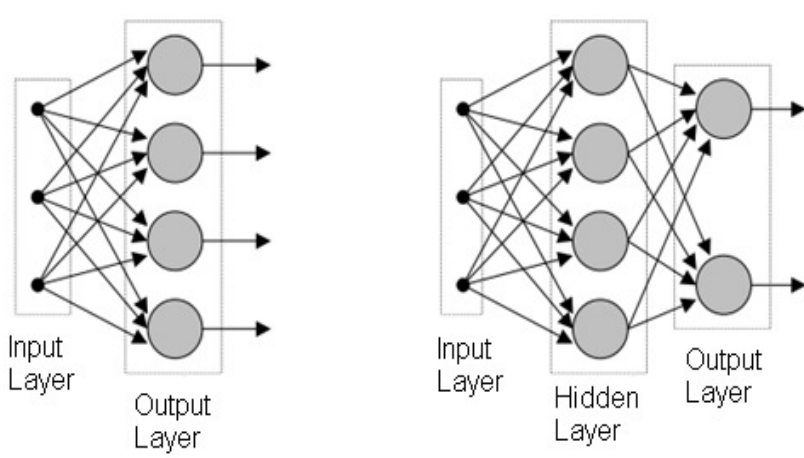

Fig. 5. Neural networks in layers: (a) with only two layers; (b) with an input layer, a hidden layer and an output layer [11].

The most basic type of neural network, the perceptron, is capable of solving only linearly separable problems. However, using multilayer neural networks with at least one hidden layer removes many perceptron problems.

Learning the network is guided by the presence of a "teacher", that is, the desired response to a given estimate presented by the environment. The error, therefore, will be the difference between the desired response and the response observed at the output.

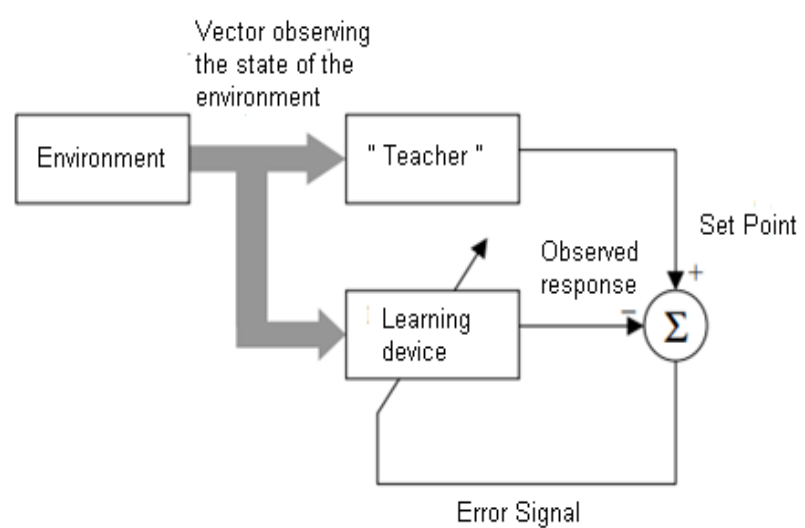

Fig. 6. Block diagram of a system with supervised learning [11]

$$
P_{k}(n)=s_{k}[n]-y_{k}(n)(1)
$$

We define a cost function, commonly used as the sum of the quadratic errors, which must be minimized for network optimization:

$$
J=\frac{1}{2} \sum_{\mathbf{E}} \theta_{\mathrm{k}}^{2}(n)(2)
$$


In this study, a multi-layered RNA algorithm implemented in the Matlab software was used, with two layer, so that the network considers itself trained when the cost function reaches an accuracy of $10^{-6}$.

The training of the neural network was performed using the irradiation and temperature data from the city of Uberlândia and power supplied, from October of 2015 [5]. With the trained network, the weights obtained with entries referring to one day of irradiation in the month of November, in the city of Uberlândia, are used.

\section{Electrical Energy Storage System (EESS)}

For the EPS design, demand and distributed generation curves must be collected. The EPS shall use the whole or part of the difference between the two in order to remove or reduce surplus generation in the system. On the basis of Figure 1 and the power class obtained, it is also possible to define which is the storing element of electric energy suitable for the application.

\section{System Simulations}

The main active variables in this study are the total hourly active losses in the hours the battery is discharging. The system as a whole will be simulated and analyzed in OpenDSS software.

This software performs load flow calculations using the Newton-Rhapson method and provides in its basic scenario, maximum and minimum voltages, p.u., total active power, total reactive power, total active losses, and system frequency. Multiple cases will be simulated to analyze the effects of the store.

The Power Flow is calculated iteratively, using NewtonRhapson[10].

The Newton-Raphson method has a quadratic convergence rate, making it faster than other methods. However, formulating and factorizing the Jacobian matrix is a disadvantage.

\section{Results}

\section{A. Daily Photovoltaic Generation}

After the training of the neural network, the data of solar irradiation and one-day temperature of November / 2016, from the city of Uberlândia-MG [5], were inserted. In the day there was clear sky and this state is advantageous for the definition of the system as a whole, in high generation days. With the data, the graph of figure (7) was plotted:

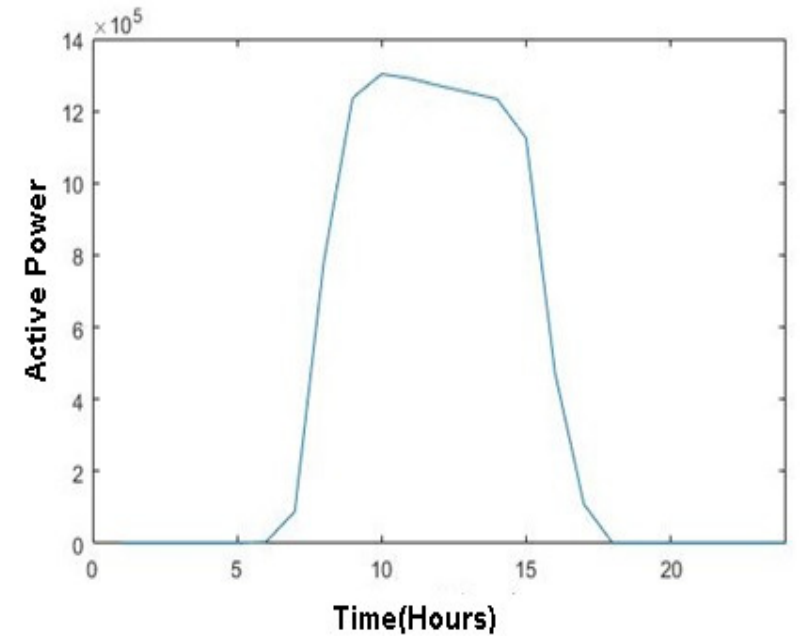

Fig. 7. Daily Photovoltaic Generation

\section{B. Electrical Energy Storage System}

In the OpenDSS, the demand curve, available in the OpenDSS library, multiplied by the total power, about $2.6 \mathrm{MW}$ according to figure (8), was also used to size the store to be inserted in the IEEE 37 Barras circuit.

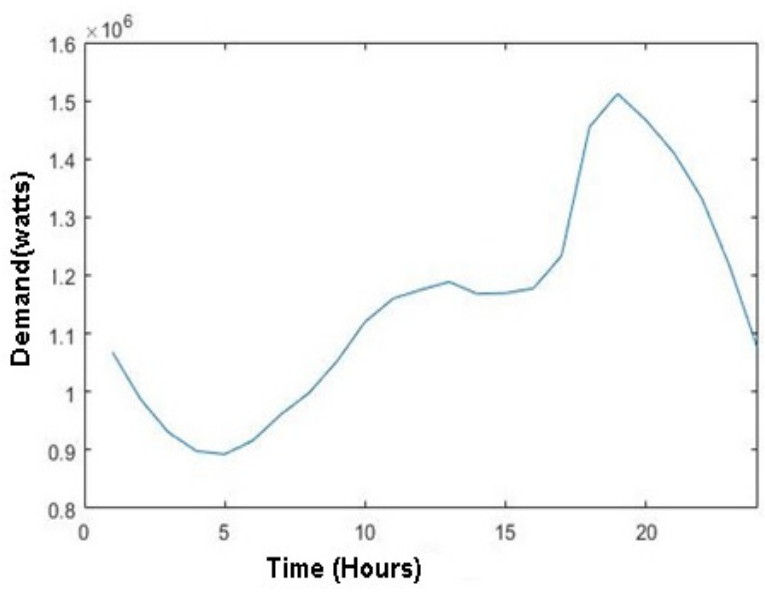

Fig. 8. Daily demand of IEEE 37 buses

The overlap of the curves (figure 9) allows the visualization of the battery charge intervals, which will be at the points where the generation curve is larger than the demand curve.

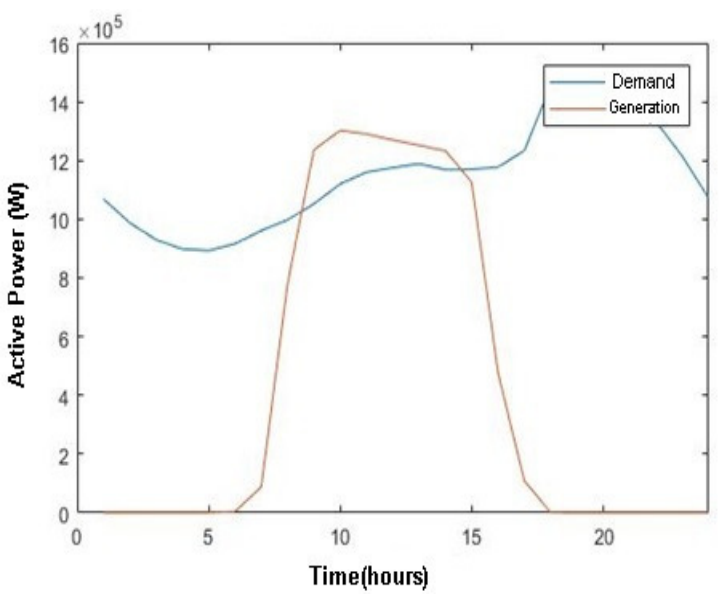

Fig. 9. Demand vs. Generation Curves 
The storage hours are then taken from 9 am to $3 \mathrm{pm}$ and the time of discharge of the EPS from $6 \mathrm{pm}$ to midnight. In this study, one-third of the surplus power available for the battery charge was used. In this way, approximately $240 \mathrm{kWh}$ will be stored during its charging period, which will be evenly distributed during its discharge period, ie about $60 \mathrm{~kW}$ per storer.

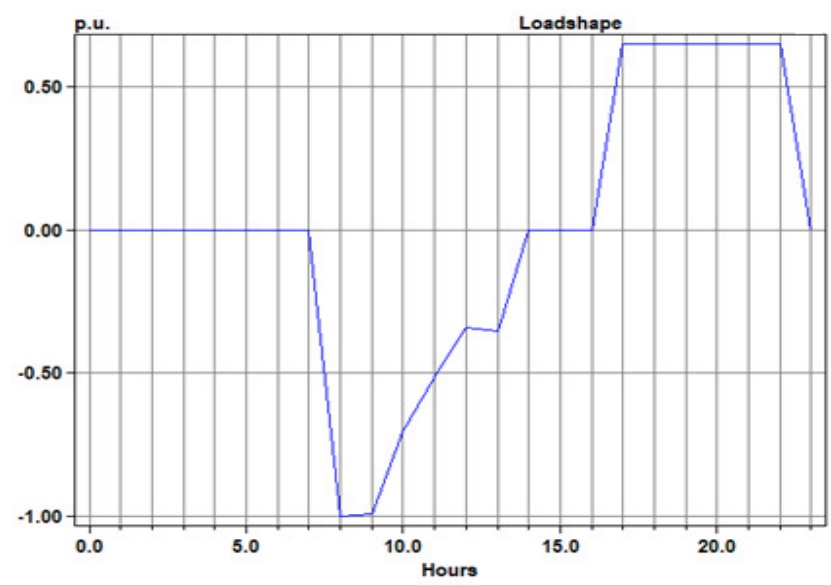

Fig. 10. Storage Cycle of Operation

Analyzing Figure 1 and Figure 10, the storehouses that best apply to this case are the flow batteries and the sodium-sulfur batteries.

\section{Losses of the IEEE 37 Bus System}

The total photovoltaic generation will be evenly distributed in three bars. For all the studies performed, the generation was allocated in bars 710,711 and 741 , in inspiration to [5]. In order to verify the effects of the storage systems in the system, the data of active power losses, reactive power losses, and minimum and minimum voltage profiles will be collected in four cases, where the storage will be evenly distributed according to the load regions of the system. Figure 1. Case study 1 has the EPS system allocated in bar 730. Study 2 has EPS system allocated in bar 738. For case study 3, EPS is uniformly distributed in buses 701, 730 and 738 and in case study 4, at bars 724, 729 and 738. For final comparison, the load flow in the system was also made without the use of storage rooms. These data were condensed into Tables 1 to 4.

In a complementary way, the study was carried out for a system that uses a system of larger warehouses with $0.9 \mathrm{MWh}$ of storage capacity and $0.15 \mathrm{MW}$ of discharge per hour. In this study, the total active losses were $298,3051 \mathrm{~kW}$, about a reduction of $22 \%$.

Table I. - Active Losses in the System

\begin{tabular}{|c|c|c|c|c|c|}
\hline \multicolumn{6}{|c|}{ Active Losses in the System [kwh] } \\
\hline Hour & $\begin{array}{c}\text { Without } \\
\text { AEE }\end{array}$ & Case 1 & Case 2 & Case 3 & Case 4 \\
\hline 18 & 66.21762 & 64.00695 & 63.62734 & 64.05916 & 63.91451 \\
\hline 19 & 69.29758 & 67.00617 & 66.60805 & 67.06058 & 66.90946 \\
\hline 20 & 66.86369 & 64.63827 & 64.25465 & 64.69093 & 64.54494 \\
\hline
\end{tabular}

\begin{tabular}{|c|c|c|c|c|c|}
21 & 63.88468 & 61.74939 & 61.38421 & 61.7999 & 61.66017 \\
\hline 22 & 59.96988 & 57.95803 & 57.61782 & 58.00557 & 57.87449 \\
\hline 23 & 54.51395 & 54.54115 & 54.54566 & 52.72813 & 52.61091 \\
\hline TOTAL & 380.7474 & 369.9 & 368.0377 & 368.3443 & 367.5145 \\
\hline
\end{tabular}

Table II. - Reactive losses in the system

\begin{tabular}{|c|c|c|c|c|c|}
\hline \multicolumn{6}{|c|}{ Reactive losses in the system [kVArh] } \\
\hline Hour & $\begin{array}{c}\text { Without } \\
\text { AEE }\end{array}$ & Case 1 & Case 2 & Case 3 & Case 4 \\
\hline 18 & 163.5800 & 157.835 & 157.5726 & 157.9220 & 157.8207 \\
\hline 19 & 171.5220 & 165.5731 & 165.2947 & 165.6639 & 165.5574 \\
\hline 20 & 165.2460 & 159.4408 & 159.1979 & 159.5517 & 159.4493 \\
\hline 21 & 157.5638 & 152.0105 & 151.7602 & 152.0941 & 151.9688 \\
\hline 22 & 147.4678 & 142.2275 & 141.9982 & 142.3057 & 142.2153 \\
\hline 23 & 133.39579 & 133.46536 & 133.46729 & 128.68988 & 128.6115 \\
\hline TOTAL & 938.7756 & 910.57596 & 909.29106 & 906.22751 & 905.6515 \\
\hline
\end{tabular}

The OpenDSS software also analyzes the voltages in all the bars and registers their minimum and maximum values, in p.u.:

Table III. - Minimum Voltage

\begin{tabular}{|c|c|c|c|c|c|c|}
\hline \multicolumn{7}{|c|}{ Minimum Voltage (p.u) } \\
\hline Hour & $\begin{array}{c}\text { Without } \\
\text { AEE }\end{array}$ & Case 1 & Case 2 & Case 3 & Case 4 & Big AEE \\
\hline 18 & 0.9896 & 0.9910 & 0.9911 & 0.9908 & 0.9908 & 0.9936 \\
\hline 19 & 0.9878 & 0.9891 & 0.9892 & 0.9890 & 0.9889 & 0.9967 \\
\hline 20 & 0.9892 & 0.9906 & 0.9907 & 0.9904 & 0.9904 & 0.9973 \\
\hline 21 & 0.9911 & 0.9923 & 0.9924 & 0.9922 & 0.9922 & 0.9981 \\
\hline 22 & 0.9922 & 0.9933 & 0.9934 & 0.9932 & 0.9932 & 0.9991 \\
\hline 23 & 0.9937 & 0.9937 & 0.9937 & 0.9947 & 0.9947 & 1.0005 \\
\hline MIN & 0.9878 & 0.9849 & 0.9892 & 0.9890 & 0.98899 & 0.9936 \\
\hline
\end{tabular}

Table IV. - Maximum Voltage

\begin{tabular}{|c|c|c|c|c|c|c|}
\hline \multicolumn{7}{|c|}{ Maximum Voltage (p.u) } \\
\hline Hour & $\begin{array}{c}\text { Without } \\
\text { AEE }\end{array}$ & Case 1 & Case 2 & Case 3 & Case 4 & $\begin{array}{c}\text { Big } \\
\text { AEE }\end{array}$ \\
\hline 18 & 1.0153 & 1.0160 & 1.0161 & 1.0159 & 1.0159 & 1.0176 \\
\hline 19 & 1.0142 & 1.0150 & 1.0150 & 1.0149 & 1.0149 & 1.019 \\
\hline 20 & 1.0150 & 1.0153 & 1.0159 & 1.0157 & 1.0157 & 1.0200 \\
\hline 21 & 1.0161 & 1.0169 & 1.0169 & 1.0168 & 1.0168 & 1.0210 \\
\hline 22 & 1.0176 & 1.0183 & 1.0184 & 1.0182 & 1.0182 & 1.0224 \\
\hline 23 & 1.0198 & 1.0198 & 1.0198 & 1.0204 & 1.0204 & 1.0244 \\
\hline MAX & 1.0198 & 1.0198 & 1.0198 & 1.0204 & 1.0204 & 1.0244 \\
\hline
\end{tabular}

\section{Analysis of Results}

Comparing the flow batteries with those of sodium sulfur, sulfur sodium batteries are favorable to this 
application due to the more advanced technology and wider pre-applications [9].

Using EPS to reduce technical losses proved feasible by comparing the cases studied. There was a reduction of about $3.5 \%$ of system losses in the fourth case. The allocation and proper distribution of the storage shows more favorable results, since in the second case, where the storage is focused on the bar 730, better results were obtained than in case 3. In this way, it is possible to optimize the distribution of the stores in order to minimize the electrical losses.

Complementing, in the last study, where a larger proportion was estimated, losses fell by $21.65 \%$. With regard to minimum voltages, the use of EPS systems led to voltage closer to the unit, in p.u, since all were less than 1 . However, EPS systems also raise maximum voltages.

\section{Conclusion}

There are concerns about the increasing factor surrounding distributed generation. However, with the application of Electrical Energy Storage systems solutions in the networks, it is possible to use this problem as power of the optimization of the systems. The application of these solutions reduces the total losses in the system and reduces the problems of over generation. All results can be converted into savings for the companies responsible for the transmission of electric energy, noting the increase in the overall voltage profile caused by ESA systems, which should not exceed technical standards.

There is also the possibility of surplus generation, which can cause problems to the network, such as power flow inversion, overvoltages, frequency variations and instability.

Power storage technologies do not only fit systems that have distributed generation. In networks whose demand curve has a very sharp peak, energy can be accumulated during the recess periods and applied when necessary, the batteries operate as a load. In networks whose generation has a strong seasonal dependence, it is also possible to plan the long-term energy accumulation by technologies such as the reversible hydroelectric plant or the storage of compressed air, where the analysis is done annually. The use of artificial neural networks is allied and is a valid tool for the use of these systems, by predicting future load and generation data.

\section{References}

[1] Empresa de Pesquisa Energética. Projeção da demanda de energia elétrica (2017-2026). Rio de Janeiro, 2017, pp. 1-94.

[2] Exame Website. Sistema elétrico mudará com expansão eólica e solar, diz ONS, 2017. Available at: https://exame.abril.com.br/economia/sistema-eletrico- mudara-com-expansao-eolica-e-solar-diz-ons/. Accessed in July 25, 2018.

[3] CERP. Geração distribuída na visão do operador e do planejador nacional do sistema. December, 2015.

[4] Kreveld, P. Rapid increase in solar installations potentially overloading the grid. 2012. Available at: http://electricalconnection.com.au/rapid-increase-sola r-installations-potentially-overloading-grid/. Accessed in August 23, 2018.

[5] Arantes, R V. A., Reconfiguração otimizada de redes de distribuição de energia elétrica com penetração fotovoltaica, com a utilização de armazenadores de energia e com o auxílio de inteligência artificial. 186 p. Doctoral dissertation (Science Doctorate) Universidade Federal de Uberlândia, Uberlândia, 2017.

[6] Zhou X., Y. Lin and Y. Ma, "The overview of energy storage technology,", in IEEE International Conference on Mechatronics and Automation (ICMA) 2015, Beijing, , pp. 43-48.

[7] Dunn B., Kamath H. and Tarascon J.M., "Electrical Energy Storage for the Grid: A Battery of Choices," in Science, vol. 334, no. 6058, pp. 928-935.

[8] SourceFore Website. OpenDSS. 2018. Available at: https://sourceforge.net/projects/electricdss/. Accessed in June 2017.

[9] Masato E. Inteligência Computacional no Projeto Automático de Redes Neurais Híbridas e Redes Neurofuzzy Heterogêneas. Master's thesis (Master of Science in Electrical Engineering), Universidade Estadual de Campinas, Campinas, 2000.

[10]Salgado. R., Fluxo de Potêcia - Método de Newton. Available at: http://www.labspot.ufsc.br/ katia/FPN R-Slg.pdf/. Accessed in March 2018.

[11] Castrounis, A. Artificial Intelligence, Deep learning and neural networks explained. 2016. Available at: https://www.kdnuggets.com/2016/10/artificialintellig ence-deep-learning-neural-networks-explained.html. Accessed in August 28, 2018. 